\title{
Pertussis surveillance and control: exploring variations and delays in testing, laboratory diagnostics and public health service notifications, the Netherlands, 2010 to 2013
}

J Heil ${ }^{12}$, HLG ter Waarbeek ${ }^{12}$, CJPA Hoebe ${ }^{12}$, PHA Jacobs ${ }^{3}$, DW van Dam ${ }^{4}$, TAM Trienekens ${ }^{5}$, JWL Cals ${ }^{6}$, IHM van Loo ${ }^{2}$, NHTM Dukers-Muijrers ${ }^{12}$

1. Department of Sexual Health, Infectious Diseases and Environmental Health, South Limburg Public Health Service, Geleen, the Netherlands

2. Department of Medical Microbiology, School of Public Health and Primary Care (CAPHRI), Maastricht University Medical Centre (MUMC+), Maastricht, the Netherlands

3. Department of Infectious Diseases Control, North Limburg Public Health Service, Venlo, the Netherlands

4. Department of Medical Microbiology and Infection Prevention, Zuyderland Medical Centre, Sittard-Geleen, the Netherlands

5. Department of Medical Microbiology, VieCuri Medical Centre, Venlo, the Netherlands

6. Department of General Practice, School of Public Health and Primary Care (CAPHRI), Maastricht University Medical Centre (MUMC+), Maastricht, the Netherlands

Correspondence: Jeanne Heil (jeanne.heil@ggdzl.nl)

Citation style for this article:

Heil J, ter Waarbeek HLG, Hoebe CJPA, Jacobs PHA, van Dam DW, Trienekens TAM, Cals JWL, van Loo IHM, Dukers-Muijrers NHTM. Pertussis surveillance and control: exploring variations and delays in testing, laboratory diagnostics and public health service notifications, the Netherlands, 2010 to 2013 . Euro Surveill. 2017;22(28):pii=30571. DOI: http://dx.doi.org/10.2807/1560-7917.ES.2017.22.28.30571

Article submitted on 03 October 2016 / accepted on 22 February 2017 / published on 13 July 2017

Pertussis is most severe among unvaccinated infants ( 1 year of age), and still leads to several reported deaths in the Netherlands every year. In order to avoid pertussis-related infant morbidity and mortality, pertussis surveillance data are used to guide pertussis control measures. However, more insight into the accuracy of pertussis surveillance and control, and into the range of healthcare and public health-related factors that impede this are needed. We analysed a unique combination of data sources from one Dutch region of 1.1 million residents, including data from laboratory databases and local public health notifications between 2010 and 2013. This large study $(n=12,090$ pertussis tests) reveals possible misdiagnoses, substantial under-notification (18\%, 412/2,301 laboratory positive episodes) and a delay between patient symptoms and notification to the local public health services (median 34 days, interquartile range (IQR): $27-54$ ). It is likely that the misdiagnoses, under-notification and overall delay in surveillance data are not unique to this area of the Netherlands, and are generalisable to other countries in Europe. In addition to preventive measures such as maternal immunisation, based on current findings, we further recommend greater adherence to testing guidelines, standardisation of test interpretation guidelines, use of automatic notification systems and earlier preventive measures.

\section{Introduction}

Bordetella pertussis and Bordetella parapertussis infections are most severe among unvaccinated infants [1-4]. Complications of the resulting disease, pertussis, include pneumonia, failure to thrive from post-tussive vomiting, seizures, secondary bacterial infection and pulmonary hypertension $[2,5]$. The full implementation of general pertussis vaccination in the 1950 s greatly reduced its incidence in the Netherlands [6] and led to a shift from cases in children to adults [5,7-9]. Even though worldwide vaccination coverage of $86 \%$ has been achieved [10], there were around 63,000 pertussis-linked deaths in children under 5 years of age in 2012 [11]. In Europe, the highest number of cases were notified by the Netherlands in 2012 ( $n=12,868)$, accounting for $30 \%$ of all notifications in Europe [12]. The Dutch incidence rate of symptomatic pertussis infections in 2011 was estimated to be 107 per 10,000 population [13].

The Netherlands has an extensive free of charge National Immunisation Programme (NIP) to protect all children against 12 infectious diseases, including pertussis [14]. The efficacy of pertussis vaccines has been debated because of waning immunity, incomplete protection of infants younger than 5 months of age, genetic changes in $B$. pertussis and limited duration of protection $[3,15,16]$. Maternal immunisation is recommended by the WHO, ECDC and by the Health Council of the Netherlands $[12,17,18]$. In England, maternal 


\section{FIGURE 1}

Possible pertussis episodes ${ }^{\mathrm{a}}$ considered positive, inconclusive and negative by laboratories ${ }^{\mathrm{b}}$, the Netherlands, 2010-2013 $(\mathrm{n}=12,090)$

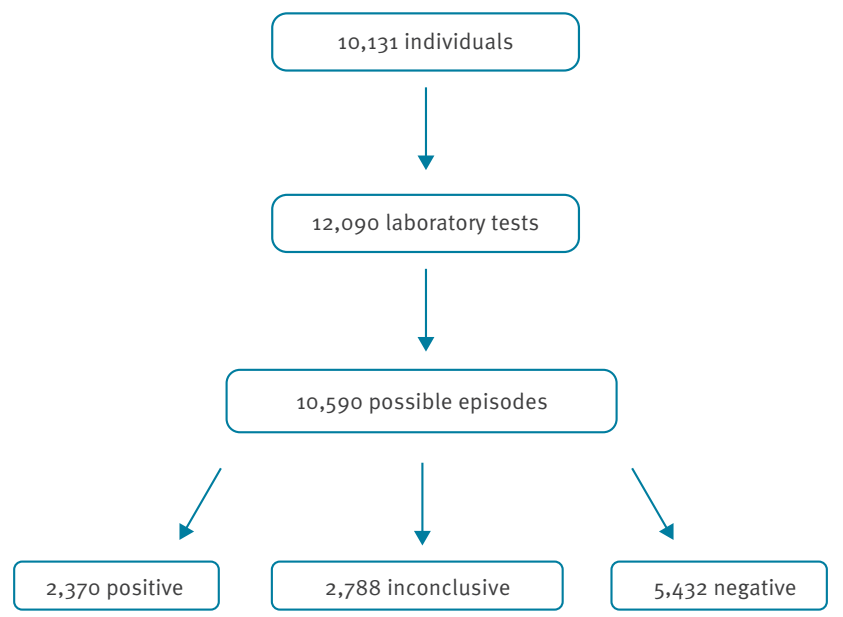

${ }^{a}$ A possible episode of pertussis disease was considered unique if the same person was tested once or more within an 8-week interval. If an individual was tested twice within an interval longer than 8-weeks, it was considered two possible pertussis episodes.

b The laboratories used different test assays, cut-off values and algorithms for interpreting serology, PCR and culture test results as positive, inconclusive or negative.

immunisation was found to have a vaccine-effectiveness of $91 \%$ in infants $<2-3$ months of age with no side effects $[19,20]$. Despite a pertussis vaccination coverage in the Netherlands of $96 \%$, increasing numbers of pertussis notifications have been observed since 1996 $[15,21,22]$, with epidemic peaks every $2-3$ years [15] and 1 to 3 pertussis-related deaths per year [14].

Pertussis is a notifiable disease in the Netherlands according to Wet Publieke Gezondheid, the law that requires notification of NIP-targeted diseases [23]. Local public health services (PHS) must be notified when: (i) patients have typical symptom(s) or (ii) patients have at least 14 days of coughing, combined with either a positive laboratory test or recent contact with a confirmed pertussis case [24]. Legally, both healthcare providers (HCPs) and laboratories are responsible for notification, but in practice, most notifications originate from the laboratories. Local PHS collect and verify all notifications, advise patients' HCPs on vaccination and/or medical treatment of contacts, and report cases to the National Institute for Public Health and the Environment (RIVM). An overview of the guidelines and criteria for pertussis testing, diagnostics and notifications in the Netherlands is provided in Table 1.

Pertussis surveillance aims to monitor the impact of the vaccination programme, identify high-risk areas and detect outbreaks, monitor case management and take timely preventive measures [25]. However, pertussis surveillance and control are greatly hampered by, for example, under-ascertainment as individuals with mild symptoms or who are asymptomatic may not present to healthcare for diagnosis $[26,27]$. Clinically, the disease resembles other respiratory diseases, particularly in the early catarrhal phase when an individual is already highly contagious [26]. Also, the classical pertussis symptoms are often absent in adolescents and adults such that these cases may not be recognised by HCPs $[26,28,29]$. In $2006-2007$, the estimated seroprevalence of pertussis infections was 100-fold higher than the reported notifications at that time [15]. Laboratory diagnostic procedures, especially interpretation of serology, are complicated because of changing cut-off value recommendations, in cases of recent immunisation and the limitations of available diagnostic tests $[5,27,30]$. As the pertussis diagnostic process is quite challenging, not all cases presenting to healthcare are diagnosed (underdiagnosis) or notified (undernotification) [31]. Moreover, there is debate about how to reduce the overall delay until notification to improve pertussis control $[32,33]$.

A quantification of healthcare and public health factors that may compromise the accuracy of pertussis surveillance and quality of pertussis control in infants $<1$ year of age in day-to-day practice is missing. This study aims to assess possible pertussis misdiagnosis, under-notification and delay in laboratory testing and delay in notifications to PHS.

\section{Methods}

We evaluated the possible pertussis misdiagnosis, under-notification and delay using laboratory testing data and notification data from local PHS.

\section{Study location}

This study was conducted in Limburg, the southernmost province of the Netherlands. There are 1.1 million inhabitants and this population is comparable to the rest of the Netherlands in terms of sex composition and urbanisation, although it is slightly older [34]. All six medical microbiology laboratories in this province provided test data for this study. Notification data were retrieved from the two local PHS.

\section{Laboratory records and standardisation of results}

Laboratory data from pertussis testing requested by HCPs (general practitioners (GPs) and hospital specialists) and conducted by all laboratories in the study area between 2010 and 2013 were retrieved. The data included patient data on age, type of test performed (serology $\operatorname{lgA} / \operatorname{lgG}$, PCR and culture), type of HCP (GP or specialist), date of test request, date of test result, test result and interpretation of test result. No data on sex was reported. Based on regional GP testing-behaviour questionnaires, we estimated that the laboratory data covered at least $90 \%$ of all pertussis tests in our 
Median time of Bordetella pertussis and Bordetella parapertussis infection from first day of illness to notification of the RIVM, Limburg province, the Netherlands, 2010-2013

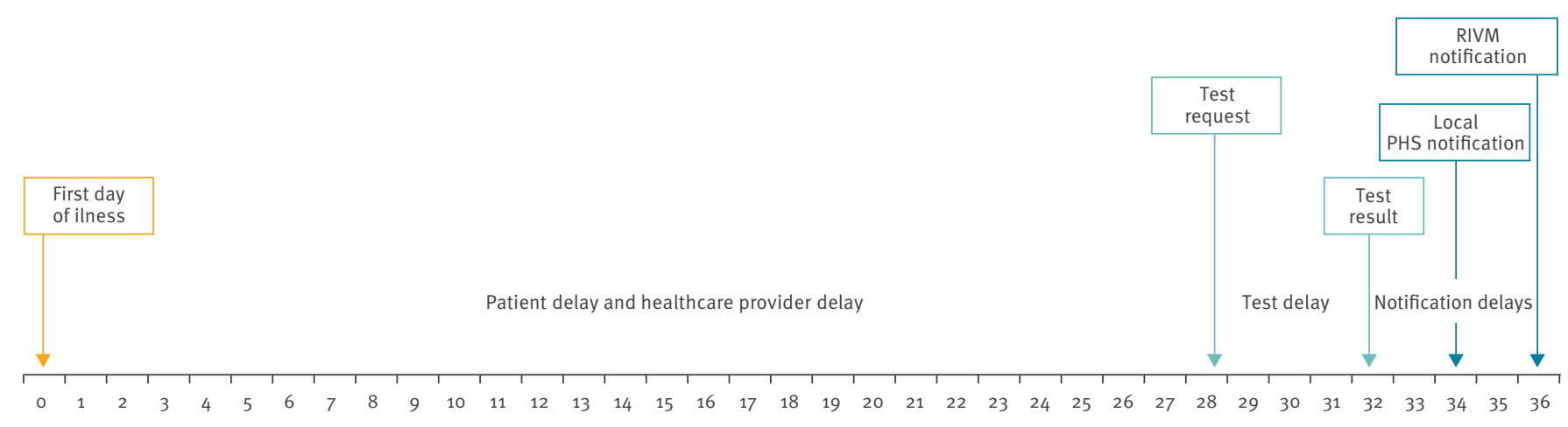

Median time (days)

PHS: public health services; RIVM: National Institute for Public Health and the Environment.

region. A total of 12,090 tests on 10,131 individuals were performed.

Laboratory tests

The laboratories used different test assays, cut-off values and algorithms for interpreting test results, including interpretation of disease duration and patient age as the sensitivity of the diagnostic tests for pertussis depends on the age of the patient and the duration of illness [35]. Whether laboratories received clinical data to include into their algorithms depends on the HCP who requested the test. $B$. pertussis IgA and/or pertussis toxin IgG ELISA from Virion/Serion (Würzburg, Germany) or Virotech (Rüsselsheim, Germany) was used for serology. The sensitivity and specificity of these serological test kits varied between $68 \%$ and $89 \%$ and between $67 \%$ and $87 \%$, respectively [36]. At one laboratory, the serological cut-off values changed on 1 September 2011. Two laboratories switched from Virotech Units (VU) to International Units (IU), one on 1 May 2011 and the other on 16 January 2012. Charcoal blood agar (Oxoid) with and without cephalexin were used for culture. Four of the laboratories used an inhouse multiplex PCR test with target gene IS481 ( $B$. pertussis) and target gene $I_{1001}$ (B. parapertussis). The other two laboratories were unable to distinguish between $B$. pertussis and $B$. parapertussis because target gene IS1002 or target gene IS481 were used.

\section{Serology interpretation}

There are a lack of uniform laboratory guidelines on serology interpretation so different cut-off values are used by laboratories across Europe [27,37]. To correct for the different cut-off values used in our study area and to detect other inter-laboratory differences, we compared laboratory test interpretation to standardised serological test results. The conversion from VU/ $\mathrm{ml}$ to $\mathrm{IU} / \mathrm{ml}$ was calculated with the following formula:

$\left((\text { number of } V U / m l /(33.3-\text { number of } V U / m l))^{1.15}\right) \times 112=I U / m l$.
A single high titre of $\lg G \geq 62.5 \mathrm{IU} / \mathrm{ml}$ or $\lg \mathrm{G} \geq 13 \mathrm{VU} / \mathrm{ml}$ was defined as positive as these cut-off values have been shown to be sensitive and specific indicators of infection in the past year $[15,38,39]$. International guidelines recommend measuring IgA antibodies with intermediate IgG levels or when no second sample can be obtained $[40,41]$. IgA antibodies were not taken into account in our standardisation as most laboratories did not use IgA antibody results in their serology interpretation. Furthermore, measuring IgA antibodies has been proven to be less specific and sensitive $[5,36]$. The standardised test result was considered positive when multiple serology was applied and all serology tests were positive, and it was considered negative when all serology tests applied were negative. When multiple serology test results were inconsistent, the standardised test result was considered positive when seroconversion occurred from a negative test to a positive test result.

Notification data

Notification data were collected from the two local PHS that serve the study area. These data included date of first day of illness, notifier (laboratory/GP/hospital), date of notification to PHS, date of notification to national notification system of RIVM and information on preventive measures taken by the PHS, including giving advice and providing vaccination or prophylaxes to at-risk contacts.

\section{Statistical analyses}

The laboratory data were analysed at the test-level and at the episode-level. Notably, a possible episode of pertussis disease was considered unique if the same individual was tested once or more within an 8-week interval. However, if an individual was tested twice within an interval longer than 8-weeks it was considered two possible pertussis episodes. Descriptive statistics and chi-squared tests were used to compare 
TABLE 1

Pertussis testing, diagnostics and notification guidelines and criteria, the Netherlands, 2010-2013

\begin{tabular}{|c|c|c|}
\hline Actor & Responsibility & Guidelines/criteria \\
\hline \multirow{5}{*}{$\begin{array}{l}\text { Healthcare } \\
\text { provider }\end{array}$} & Clinical diagnostic & $\begin{array}{l}\text { Patients with typical symptoms } s^{a} \text { or, during epidemics, patients with severe coughing who } \\
\text { have had contact with a proven pertussis case [45]. }\end{array}$ \\
\hline & $\begin{array}{l}\text { Requests for laboratory } \\
\text { testing }\end{array}$ & $\begin{array}{l}\text { When pertussis is suspected in a patient whose family includes unvaccinated or } \\
\text { incompletely vaccinated infants }<1 \text { year of age or a woman }>34 \text { weeks pregnant [45]. } \\
\text { Test method for: } \\
\text { - Infants }<1 \text { year of age, PCR or culture } \\
\text { - Individuals }>1 \text { year of age and with }>3 \text { weeks of coughing, serology } \\
\text { - Individuals }>1 \text { year of age and with }<3 \text { weeks of coughing, PCR }[24,40,45] \text {. }\end{array}$ \\
\hline & $\begin{array}{l}\text { Medical treatment of } \\
\text { index case and/or at-risk } \\
\text { contacts }\end{array}$ & $\begin{array}{l}\text { First confirm the clinical diagnoses of the index case by laboratory test. In a possible } \\
\text { index case whose family includes unvaccinated or incompletely vaccinated infants } 11 \\
\text { year of age, a woman }>34 \text { weeks pregnant or a child with severe heart or lung failure, } \\
\text { treatment is indicated for all family members and can start before laboratory confirmation } \\
\text { of the index case. Medical treatment outside the family only occurs after PHS advice and } \\
\text { laboratory confirmation of the index case }[24,45] \text {. } \\
\text { Preferably, start treatment of the index case within } 3 \text { weeks of illness onset }[24,45] \text {. }\end{array}$ \\
\hline & $\begin{array}{l}\text { Vaccination of at-risk } \\
\text { contacts }\end{array}$ & $\begin{array}{l}\text { Administer first vaccination prior to vaccination of NIP or administer vaccination to } \\
\text { unvaccinated or incompletely vaccinated children }<5 \text { years old in the family }[24,45] \text {. }\end{array}$ \\
\hline & $\begin{array}{l}\text { Notification of local PHS } \\
{[23]}\end{array}$ & $\begin{array}{l}\text { Patients with typical symptom }(\mathrm{s})^{\text {a }} \text { or with at least } 14 \text { days of coughing combined with } \\
\text { either a positive laboratory test or contact within past three weeks with a confirmed } \\
\text { pertussis case [24]. } \\
\text { Notify within one workday [44]. }\end{array}$ \\
\hline \multirow[b]{2}{*}{ Laboratory } & Laboratory diagnostics & $\begin{array}{l}\text { Interpret as positive for pertussis when detection of } B \text {. pertussis or } B \text {. parapertussis or } \\
\text { high antibody titre in single serology } \mathrm{y}^{\mathrm{b}} \text { or significant increase of titre in multiple serology. }\end{array}$ \\
\hline & $\begin{array}{l}\text { Notification of local PHS } \\
\text { [23] }\end{array}$ & $\begin{array}{l}\text { Patients with typical symptom }(\mathrm{s})^{\text {a }} \text { or with at least } 14 \text { days of coughing combined with } \\
\text { either a positive laboratory test or contact within past three weeks with a confirmed } \\
\text { pertussis case [24]. } \\
\text { Notify within one workday [44]. }\end{array}$ \\
\hline \multirow{2}{*}{$\begin{array}{l}\text { Local public health } \\
\text { services }\end{array}$} & Surveillance & $\begin{array}{l}\text { Collect notifications and clinical data from HCPs and laboratories and report it to RIVM } \\
\text { [23]. } \\
\text { Notify within one week [44]. }\end{array}$ \\
\hline & $\begin{array}{l}\text { Medical treatment and/or } \\
\text { vaccination advice to the } \\
\text { patient's HCP }\end{array}$ & dvice on medical treatment and vaccination according to national guidelines. \\
\hline
\end{tabular}

HCP: healthcare provider; NIP: National Immunisation Programme; PHS: public health services; RIVM: National Institute for Public Health and the Environment.

a Typical symptoms include paroxysmal coughing, a whooping sound after coughing or vomiting after coughing [24].

b Single serological testing is not suitable to detect recent infection in individuals vaccinated with an acellular pertussis vaccine within the past year. Multiple serology is also recommended when the first titre is below the cut-off value specific for a pertussis infection [24].

categorical variables such as type of HCP, laboratory, type of test and year of test.

Independent sample t-tests were performed to study differences in delay. For analyses of the notification data, we used descriptive statistics. Analyses were performed using the SPSS package version 21.0 (IBM Inc., Somers, New York, United States).

\section{Results}

\section{Possible misdiagnosis (underdiagnosis and} overdiagnosis) of pertussis

Of all HCP-requested pertussis tests done in the study region in $2010-2013(n=12,090)$, the majority $(81 \%$, $\mathrm{n}=9,818$ ) were requested by GPs, varying from $72 \%$ to $88 \%$ per laboratory $(p<0.001)$. The remaining pertussis tests were requested by hospital specialists (19\%, $n=2,272)$. Most tests $(93 \%, n=11,190)$ were serological tests, $6 \%(n=729)$ were PCR tests and culture was performed in $1 \%(n=171)$. This distribution of test type differed between laboratories, ranging from, for example, $77 \%$ to $99 \%$ for serological tests ( $p<0.001$ ). Serological tests were more likely to be requested by GPs $(95 \%, n=9,275)$ compared with hospital specialists $(84 \%, n=1,915), p<0.001$.

In $44 \%(134 / 303)$ of tested infants $<1$ year of age, serology was performed instead of the recommended PCR or culture (Table 2). This proportion differed by laboratory, varying from $24 \%$ to $70 \%$ ( $p<0.001$ ) and decreased over time, from $64 \%$ in 2010 to $33 \%$ in 2013 ( $p<0.01$ ). In these infants, GPs requested serology more often $(65 \%, 52 / 80)$ than hospital specialists $(37 \%, 82 / 223)$, $\mathrm{p}<0.001$.

In total, 10,590 possible pertussis episodes were identified between 2010 and 2013 (Figure 1). Overall, $22 \%(n=2,370)$ of these possible episodes were interpreted by the laboratory as positive, with this varying between laboratories (15\% to $28 \%$ ) and over time (from $11 \%$ in 2010 to $27 \%$ in 2012 ) without a clear trend, 
Recommended tests and performed serology pertussis testing stratified into age groups, the Netherlands, 2010-2013

\begin{tabular}{|l|c|c|c|c|}
\hline Age group & $\begin{array}{c}\text { Recommended test } \\
{[24,40,45]}\end{array}$ & $\begin{array}{c}\text { Total number of performed } \\
\text { tests } \\
(\mathrm{n}=12,090)\end{array}$ & $\begin{array}{c}\text { Number of performed } \\
\text { serology tests } \\
(\mathrm{n}=11,190)\end{array}$ & $\begin{array}{c}\text { Percent of performed } \\
\text { serology tests }(\%)\end{array}$ \\
\hline <1 year & PCR or culture & 303 & 134 & 44 \\
\hline >1 year with >3 weeks of coughing & Serology & 11,787 & 11,056 & 94 \\
\hline >1 year with <3 weeks of coughing & PCR & & 94 \\
\hline
\end{tabular}

p $<0.001$. Serological tests had higher positivity rates (23\%, 2,276/9,736) compared to PCR tests and culture with positivity rates of $12 \%(83 / 715)$ and $8 \%(11 / 139)$ respectively, $\mathrm{p}<0.001$.

Furthermore, in $26 \%(n=2,788)$ of the possible episodes, no conclusive laboratory test interpretation was available. These tests were inconclusive due to missing additional serological testing $(n=1,520)$, missing clinical data such as the first day of illness $(n=321)$, the possibility of past infections or antibodies after vaccination $(n=214)$ and no/dubious result available $(n=733)$. The proportion of possible episodes with an inconclusive laboratory result varied between laboratories (o\% to 60\%) and increased over time (from 18\% in 2010 to $35 \%$ in 2013), $p<0.001$.

Of all possible pertussis episodes with an available IgGtitre $(n=8,929), 22 \%(n=1,998)$ were positive according to the laboratory and $19 \%(n=1,700)$ appeared positive after standardisation. This standardised positivity rate varied between laboratories (15\% to 23\%) and over time ( $9 \%$ in 2013 to $24 \%$ in 2012), $p<0.001$. Of all episodes considered positive by the laboratory, $32 \%(n=644)$ were negative after standardisation. This was due to high IgA-titres in combination with IgGtitres below $62.5 \mathrm{IU} / \mathrm{ml}$. Of all inconclusive episodes, $9 \%(n=248)$ were positive after standardisation. This was due to the use of a grey area in both the interpretation of IgA- and IgG-titres of some laboratories in combination with IgG-titres higher or equal to $62.5 \mathrm{IU} /$ ml. Of all negative episodes, $2 \%(n=98)$ were positive after standardisation (Table 3 ).

\section{Under-notification of pertussis}

Of all notifications to local PHS between 2010 and 2013 $(n=2,241), 93 \%(n=2,090)$ were notified by a laboratory. The remaining notifications were by a GP (3\%), a hospital ( $2 \%)$ or others ( $2 \%)$. Of the total number of laboratory-positive episodes of persons living in the study region $(n=2,301), 412(18 \%)$ were not notified to the PHS. This under-notification varied between laboratories from $10 \%$ to $39 \%$, and varied from $13 \%$ in 2011 to $59 \%$ in 2010 with no trend, $p<0.001$. All notifications were evaluated and verified by the local PHS, which were only able to take timely preventive measures, such as giving advice or providing vaccination or prophylaxes to at-risk contacts, in $1 \%(n=26)$ of all notifications.

\section{Delay in pertussis control cascade}

The median time between patients' first day of illness and $\mathrm{HCP}$ request for a laboratory test, patient and HCP delay, was 28 days (interquartile range (IQR): 21-47) (Figure 2). It was longer for serological test requests (median=29 days, IQR: 21-49) compared with PCR or cultures (median $=18$ days, IQR: $13-24)$, $p<0.001$. For infants, this delay was shorter (median $=12$ days, IQR: 6-19) compared with all other ages (median $=28$ days, IQR: 21-48), p<0.05. Of all laboratory notifications, $28 \%(n=571)$ were tested within 3 weeks. Median time from a requested laboratory test to a test result, median test delay, was 4 days (IQR: $3-7$ ). The median test delay was longest for culture (7 days) and shortest for PCR and serology (4 days), $p<0.001$. In terms of notification delay, the median time between patients' first day of illness to local PHS notification was 34 days (IQR: 27-54). Of all laboratory notifications, $12 \%$ $(n=245)$ were notified to the local PHS within 3 weeks. It then took local PHS a median of 2 days (IQR: 0-5) to collect all patient and patient contacts information for a proper risk assessment and to notify RIVM. This is usually done by contacting HCPs for further essential risk information in order to decide on any necessary preventive measures. In $96 \%(1,538 / 1,601)$ of the notifications, it took less than 7 days for the local PHS report to the national system of RIVM.

\section{Discussion}

This study reveals possible pertussis misdiagnosis by both HCPs and laboratories, substantial under-notification of positive pertussis episodes by laboratories, and a large delay in the pertussis control cascade. All these factors negatively impact control strategies and jeopardise the effectiveness of the national pertussis surveillance system. The accuracy of pertussis surveillance is of urgent interest to all countries using notification data to guide pertussis surveillance and control. In our study, large variations in test behaviour, laboratory assays used, test interpretation and notification behaviour were observed between HCPs and between laboratories in the pertussis diagnostic process. This variation is likely to cause the accuracy of surveillance data to be different at the local level, yet which areas are more accurate than other areas is unknown. These results are also likely applicable to the other countries in Europe with similar surveillance systems considering 
Standardised test results for possible pertussis episodes using serology with available IgG-titres, Limburg province, the Netherlands, 2010-2013

\begin{tabular}{|c|c|c|c|c|c|c|}
\hline \multirow{2}{*}{$\begin{array}{l}\text { Laboratory interpretation } \\
\text { of possible episodes with } \\
\text { Ig titres } \\
(\mathrm{n}=8,929)\end{array}$} & \multicolumn{3}{|c|}{ Standardised $d^{a}$ result negative $(n=7,229)$} & \multicolumn{3}{|c|}{$\begin{array}{l}\text { Standardised } d^{\text {a }} \text { result positive } \\
\qquad(\mathrm{n}=1,700)\end{array}$} \\
\hline & Number (n) & $\begin{array}{l}\text { Percent } \\
(\%)\end{array}$ & $\begin{array}{c}\text { Variation between laboratories } \\
\text { (range of \%) }\end{array}$ & Number (n) & $\begin{array}{l}\text { Percent } \\
(\%)\end{array}$ & $\begin{array}{c}\text { Variation between } \\
\text { laboratories (range of \%) }\end{array}$ \\
\hline Positive $(n=1,998)$ & 644 & 32 & $0-57^{b}$ & 1,354 & 68 & $43-100^{b}$ \\
\hline Inconclusive $(n=2,672)$ & 2,424 & 91 & $45-95^{c}$ & 248 & 9 & $5-55^{c}$ \\
\hline Negative $(n=4,259)$ & 4,161 & 98 & $90-100$ & 98 & 2 & $0-10$ \\
\hline
\end{tabular}

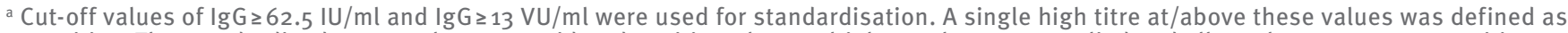
positive. The standardised test result was considered positive when multiple serology was applied and all serology tests were positive, and it was considered negative when all serology tests applied were negative. When multiple serology test results were inconsistent, the standardised test result was considered positive when seroconversion occurred from a negative test to a positive test result.

${ }^{b} p<0.01$.

c $p<0.001$

the generalisability of misdiagnosis, under-notification and overall delay in surveillance data.

Just slightly over half of the infants were tested for pertussis using the recommended PCR or culture. Furthermore, a quarter of possible episodes in all ages lacked a conclusive laboratory test result. These results show the possibility of misdiagnosis and the complexity of the pertussis diagnostic process both for HCPs and for the laboratories. It is unknown whether the possible misdiagnoses caused underdiagnosis or overdiagnosis. The standardisation of test results using IgG-titres revealed that positivity rate differences between laboratories remained after correcting for the different cut-off values used. Laboratory differences in test interpretation, the variation in tests used and positivity rates have also been found in prior studies $[5,27,30]$.

Our study shows that almost one fifth of all laboratory pertussis diagnoses were not notified to the local PHS. A comparable under-notification rate has been reported in Italy [42]. Administrative and logistical problems are possible contributors to this under-notification. In the laboratory that used an automatic digital notification system, there was less under-notification (10\%) compared to the other laboratories, $p<0.001$.

There was a considerable delay in the national surveillance data. Overall, it took a median of 34 days from first day of illness before the local PHS was notified, and only $12 \%$ of all laboratory notifications were reported within three weeks, which is comparable to other Dutch findings $[32,43]$. Time from the laboratory test result to local PHS notification and from local PHS to RIVM was in accordance with the guidelines [44]. However, time from the first day of illness to a laboratory test request was 28 days, while pertussis remains contagious up to 3-4 weeks after the first symptoms [5]. Clinical diagnosis and diagnosis after laboratory testing is therefore made too late to start treatment or take any necessary preventive measures. Adequate and early diagnosis followed by antibiotic treatment is particularly important as it can prevent further transmission to infants, HCPs and pregnant women [21]. For optimal effectiveness, treatment has to be started early after onset of illness as pertussis is no longer present in respiratory secretions after about 3 weeks [45]. The long patient and/or HCP delay seen in this study therefore limits early treatment and optimal pertussis control.

This study benefited from a large sample size and having complete regional data via a large database that included around $90 \%$ of laboratory tests for pertussis in one geographical area. Another strength was the availability of information on advice given or preventive measures taken by the local PHS for all notifications. Moreover, we studied data from across the pertussis control chain for both healthcare as well as public health. However, data on patient symptoms, disease awareness or healthcare-seeking behaviour were lacking. We were therefore unable to assess these patient-related factors as an explanation for patient delay. More information on the HCP's reasons to test for pertussis would have been desirable. It would be of interest to know whether they initiated any preventive measures for close contacts since notification often comes too late for local PHS to take action. Given that date of consultation was not known, we were unable to identify how much delay was attributable to patient and HCP delay, respectively. We were also unable to estimate under-notifications specifically for notifications by GPs or hospital specialists since we have no data on the number of clinical diagnoses. At last, the standardisation of laboratory results was only based on IgG antibodies and did not take any clinical data like vaccination status, duration of coughing or age into account. This meant that we were not able to estimate possible false positives or false negatives, but this limited standardisation does illustrate differences 
between laboratories that could lead to local differences in diagnosis or misdiagnosis.

\section{Conclusion and recommendations}

In conclusion, this study revealed several factors that prevent good pertussis control by PHS by contributing to misdiagnosis, under-notification and delay in notifications. These factors include suboptimal testing behaviour, laboratory diagnostic procedures, and notification behaviour. While the number of notifications are the current basis for pertussis surveillance, the accuracy of this indicator for disease occurrence and as a management tool is likely poor.

The accuracy of surveillance would be improved by focusing on the factors identified here. First, to reduce misdiagnosis and the variation in pertussis diagnostics, we recommend that laboratories and HCPs improve their adherence to national guidelines about when to perform which type of test and on whom. A national uniform guideline on serology cut-off values and the use of IgA and/or IgG is desirable. Testing all patients presenting with cough is not feasible as previous research has shown that only $3 \%$ of adult patients in 12 European countries presenting with acute cough in primary care had evidence of an acute pertussis infection [46]. In the Netherlands, the current pertussis incidence is largely the result of testing and more testing would not necessarily improve pertussis control [47]. Therefore, HCPs should focus more on diagnosing patients with pertussis-like symptoms who have pregnant women or infants in their proximity. Second, to reduce under-notification, laboratories and HCPs could benefit from using an automated notification system. Third, as public health is almost always too late to intervene, preventive measures should be carried out earlier in the pertussis control chain of actions. GPs, midwives and child care workers could play a major role here. Creating awareness among these professionals and patients about taking timely preventive measures could lead to lower individual disease burden and increased pertussis care cost-effectiveness. Additional preventive measures such as the recommended maternal vaccination [18] and shortening the chain of actions would contribute to improving the surveillance system and more importantly, preventing pertussis infection, morbidity and mortality prevention in infants.

\section{Acknowledgements}

We wish to thank Jos Bus (Zuyderland Medical Centre, Heerlen), Trix van Dijke (Laurentius Hospital, Roermond and St. Jans Gasthuis, Weert) for involvement in data collection. This work was supported by the National Institute for Public Health and the Environment - Centre for Infectious Disease Control (RIVM-Clb), the Netherlands (Grant number: 3910007379).

\section{Conflict of interest}

None declared.
Authors' contributions

JH, ND, CH, HtW, PJ, IVL and JC conceptualised and designed the study. IVL, DvD, TT and JC were involved in data collection. JH cleaned the data. Both JH and ND drafted the initial manuscript and analysed the data. All authors have seen, reviewed and/or revised the manuscript and approved the final manuscript.

\section{References}

1. WHO. Pertussis vaccines: WHO position paper - September 2015.Wkly Epidemiol Rec. 2015;90(35):433-58.PMID: 26320265

2. Pluta RM, Lynm C, Glass RM. Pertussis.JAMA. 2010;304(8):922. DOI: 10.1001/jama.304.8.922 PMID: 20736479

3. Locht C, Mielcarek N. New pertussis vaccination approaches: en route to protect newborns?FEMS Immunol Med Microbiol. 2012;66(2):121-33. DOI: 10.1111/j.1574-695X.2012.00988.x PMID: 22574832

4. van der Maas NAT, Mooi FR, Berbers GAM, Swaan C, de Greeff S, de Melker HE. Kinkhoest, terug van weggeweest. [Recurrence of pertussis]. Infectieziekten Bulletin. 2012;23(8):229-34. Dutch. Available from: http://www.rivm.nl/ dsresource?objectid=a57c96e4-a421-4e81-a292-92aeebb5092C \&type=org\&disposition=inline

5. Crowcroft NS, Pebody RG. Recent developments in pertussis. Lancet. 2006;367(9526):1926-36. DOI: 10.1016/So1406736(06)68848-X PMID: 16765762

6. van Wijhe $M$, McDonald SA, de Melker HE, Postma MJ, Wallinga J. Effect of vaccination programmes on mortality burden among children and young adults in the Netherlands during the 2oth century: a historical analysis.Lancet Infect Dis. 2016;16(5):5928. DOI: 10.1016/S1473-3099(16)00027-X PMID: 26873665

7. Pebody RG, Gay NJ, Giammanco A, Baron S, Schellekens J, Tischer A, et al. The seroepidemiology of Bordetella pertussis infection in Western Europe. Epidemiol Infect. 2005;133(1):15971. DOI: $10.1017 /$ So950268804003012 PMID: 15724723

8. Zepp F, Heininger U, Mertsola J, Bernatowska E, Guiso N, Roord J, et al. Rationale for pertussis booster vaccination throughout life in Europe. Lancet Infect Dis. 2011;11(7):557-70. DOI: 10.1016/S1473-3099(11)70007-X PMID: 21600850

9. von König CH, Halperin S, Riffelmann M, Guiso N. Pertussis of adults and infants. Lancet Infect Dis. 2002;2(12):744-50. DOI: 10.1016/S1473-3099(02)00452-8 PMID: 12467690

10. World Health Organization (WHO). Global and regional immunization profile. Geneva: WHO; 2017. Available from: http://www.who.int/immunization/monitoring_surveillance/ data/gs_gloprofile.pdf?ua $=1$

11. World Health Organization (WHO). Global Health Observatory Data Respository. By category $>$ Mortality and global health estimates $>$ Child mortality $>$ Causes of child death $>$ Number of deaths by cause > By region > World. Geneva: WHO. [Accessed 26 Sep 2016]. Available from: http://apps.who.int/gho/data/ node.main.ChildMortREG10o?lang=en.

12. European Centre for Disease Prevention and Control (ECDC). Annual epidemiological report 2014 - Vaccine-preventable diseases. Stockholm: ECDC; 2014.Available from: https:// ecdc.europa.eu/sites/portal/files/media/en/publications/ Publications/AER-2014-VPD-FINAL.pdf

13. McDonald SA, Teunis P, van der Maas N, de Greeff S, de Melker H, Kretzschmar ME. An evidence synthesis approach to estimating the incidence of symptomatic pertussis infection in the Netherlands, 2005-2011. BMC Infect Dis. 2015;15(1):588. DOI: $10.1186 /$ s12879-015-1324-y PMID: 26715486

14. Schurink-van 't Klooster TM, de Melker HE. The National Immunisation Programme in the Netherlands: Developments in 2013. Bilthoven: National Institute for Public Health and the Environment (RIVM); 2013. Available from: http://www.rivm.nl/ bibliotheek/rapporten/150202002.pdf

15. de Greeff SC, de Melker HE, van Gageldonk PGM, Schellekens JFP, van der Klis FRM, Mollema L, et al. Seroprevalence of pertussis in The Netherlands: evidence for increased circulation of Bordetella pertussis. PLoS One. 2010;5(12):e14183. DOI: 10.1371/journal.pone.0014183 PMID: 21152071

16. Cherry JD. Why do pertussis vaccines fail?Pediatrics. 2012;129(5):968-70. DOI: 10.1542/peds.2011-2594 PMID: 22529282

17. WHO. Pertussis vaccines: WHO position paper, August 2015--Recommendations.Vaccine. 2016;34(12):1423-5. DOI: 10.1016/j.vaccine.2015.10.136 PMID: 26562318

18. Gezondheidsraad. Vaccinatie tegen kinkhoest: doel en strategie. [Vaccination against pertussis: aims and strategy]. 
The Hague: Gezondheidsraad; 2015. Dutch. Available from: https://www.gezondheidsraad.nl/sites/default/files/201529_ vaccinatie_tegen_kinkhoestdoel_en_strategie.pdf

19. Amirthalingam G, Andrews N, Campbell H, Ribeiro S, Kara E, Donegan K, et al. Effectiveness of maternal pertussis vaccination in England: an observational study. Lancet. 2014;384(9953):1521-8. DOI: 10.1016/S0140-6736(14)60686-3 PMID: 25037990

20. Dabrera G, Amirthalingam G, Andrews N, Campbell H, Ribeiro S, Kara E, et al. A case-control study to estimate the effectiveness of maternal pertussis vaccination in protecting newborn infants in England and Wales, 2012-2013. Clin Infect Dis. 2015;60(3):333-7. DOI: 10.1093/cid/ciu821 PMID: 25332078

21. de Greeff S, de Melker HE, Mooi FR. Kinkhoest in Nederland. [Pertussis in the Netherlands]. Ned Tijdschr Geneeskd. 2010;154: A1383. Dutch. Available from: https://www.ntvg.nl/ artikelen/kinkhoest-nederland/artikelinfo PMID:20170575

22. de Greeff SC, Mooi FR, Schellekens JFP, de Melker HE. Impact of acellular pertussis preschool booster vaccination on disease burden of pertussis in The Netherlands.Pediatr Infect Dis J. 2008;27(3):218-23. DOI: 10.1097/INF.ob013e318161a2b9 PMID: 18277916

23. Wet Publieke Gezondheid. [Public Health Act]. Pub. L. No. BWBRo024705. (9 Oct 2008). Dutch. Available from: http:// wetten.overheid.nl/BWBRo024705/2016-08-01

24. National Institute for Public Health and the Environment (RIVM). LCI - richtlijn kinkhoest. [LCI guideline on pertussis]. Bilthoven: RIVM; 2012. Dutch. Available from: http://www. rivm.nl/dsresource?objectid $=c 81$ bbf6c-1047-476b-bfbd-057f7a de3614\&type =pdf\&disposition=inline

25. World Health Organization (WHO). WHO-recommended standards for surveillance of selected vaccine-preventable diseases. Geneva: WHO; 2003. Available from: http://apps. who.int/iris/bitstream/10665/68334/1/WHO V-B_03.01_eng. pdf

26. Wood N, McIntyre P. Pertussis: review of epidemiology, diagnosis, management and prevention.Paediatr Respir Rev. 2008;9(3):201-11, quiz 211-2. DOI: 10.1016/j.prrv.2008.05.010 PMID: 18694712

27. He Q, Barkoff AM, Mertsola J, Glismann S, Bacci S. High heterogeneity in methods used for the laboratory confirmation of pertussis diagnosis among European countries, 2010: integration of epidemiological and laboratory surveillance must include standardisation of methodologies and quality assurance.Euro Surveill. 2012;17(32):20239.PMID: 22913939

28. Winter K, Harriman K, Zipprich J, Schechter R, Talarico J, Watt J, et al. California pertussis epidemic, 2010. J Pediatr. 2012;161(6):1091-6. DOI: 10.1016/j.jpeds.2012.05.041 PMID: 22819634

29. Barret AS, Ryan A, Breslin A, Cullen L, Murray A, Grogan J, et al. Pertussis outbreak in northwest Ireland, January - June 2010. Euro Surveill. 2010;15(35):19654.PMID: 20822735

30. Dempsey AF, Cowan AE, Broder KR, Kretsinger K, Stokley $S$, Clark SJ. Diagnosis and testing practices for adolescent pertussis among a national sample of primary care physicians.Prev Med. 2009;48(5):500-4. DOI: 10.1016/j. ypmed.2009.02.020 PMID: 19264095

31. Solano R, Crespo I, Fernández MI, Valero C, Álvarez MI, Godoy $P$, et al. Underdetection and underreporting of pertussis in children attended in primary health care centers: Do surveillance systems require improvement? Am J Infect Control. 2016;44(11):e251-6. DOI: 10.1016/j.ajic.2016.03.033 PMID: 27184210

32. Bonačić Marinović A, Swaan C, van Steenbergen J, Kretzschmar M. Quantifying reporting timeliness to improve outbreak control.Emerg Infect Dis. 2015;21(2):209-16. DOI: 10.3201/ eid2102.130504 PMID: 25625374

33. Kraaij - Dirkzwager M. Ottovay K, Kardamanidis K, Swaan C. Melding op tijd of te laat? Terugkoppelingsrapportages aan GGD hebben meerwaarde. [Notification in time or too late? Feedback reports to PHS have added value]. Infectieziekten Bulletin. 2015;26(8):175-9. Dutch. Available from: http://www. rivm.nl/dsresource?objectid $=78965 \mathrm{~b} 5 \mathrm{f}-854 \mathrm{~b}-4 \mathrm{cb} 4$-bd $9 \mathrm{f}-\mathrm{fco} 2 \mathrm{ff}$ 4C4C5a\&type $=$ org \&disposition $=$ inline

34. Centraal Bureau voor de Statistiek (CBS). Regionale kerncijfers Nederland. [Regional key figures the Netherlands]. The Hague: CBS. [Accessed 26 Sep 2016]. Dutch. Available from: http:// statline.cbs.nl/Statweb/publication/?DM $=S L N L \& P A=70072 N E$ $\mathrm{D}_{2} \mathrm{D}_{1}=1-2,12-23,42-45,51-56 \& \mathrm{D}_{2}=0,16 \& \mathrm{D}_{3}=18 \& \mathrm{HDR}=\mathrm{T} \& \mathrm{STB}=$ $\mathrm{G} 1, \mathrm{G} 2 \& \mathrm{VW}=\mathrm{T}$

35. van der Zee A, Schellekens JF, Mooi FR. Laboratory Diagnosis of Pertussis.Clin Microbiol Rev. 2015;28(4):1005-26. DOI: 10.1128 / CMR.00031-15 PMID: 26354823

36. Riffelmann M, Thiel K, Schmetz J, Wirsing von Koenig $\mathrm{CH}$. Performance of commercial enzyme-linked immunosorbent assays for detection of antibodies to Bordetella pertussis.J Clin
Microbiol. 2010;48(12):4459-63. DOI: 10.1128/JCM.01371-10 PMID: 20943873

37. Xing D, Markey K, Newland P, Rigsby P, Hockley J, He Q. EUVAC. NET collaborative study: evaluation and standardisation of serology for diagnosis of pertussis.J Immunol Methods. 2011;372(1-2):137-45. DOI: 10.1016/j.jim.2011.07.005 PMID: 21782823

38. Giammanco A, Chiarini A, Maple PA, Andrews N, Pebody R, Gay N, et al. European Sero-Epidemiology Network: standardisation of the assay results for pertussis. Vaccine. 2003;22(1):112-20. DOI: 10.1016/S0264-410X(03)00514-0 PMID: 14604578

39. de Melker HE, Versteegh FG, Conyn-van Spaendonck MA, Elvers LH, Berbers GA, van der Zee A, et al. Specificity and sensitivity of high levels of immunoglobulin $\mathrm{G}$ antibodies against pertussis toxin in a single serum sample for diagnosis of infection with Bordetella pertussis. J Clin Microbiol. 2000;38(2):800-6.PMID: 10655388

40. Guiso N, Berbers G, Fry NK, He Q, Riffelmann M, Wirsing von König CH. What to do and what not to do in serological diagnosis of pertussis: recommendations from EU reference laboratories. Eur J Clin Microbiol Infect Dis. 2011;30(3):307-12. DOI: 10.1007/s10096-010-1104-y PMID: 21069406

41. European Centre for Disease Prevention and Control (ECDC). Guidance and protocol for the serological diagnosis of human infection with Bordetella pertussis. Stockholm: ECDC; 2012. Available from: https://ecdc.europa.eu/sites/portal/files/ media/en/publications/Publications/bordetella-pertussisguidance-protocol-serological-diagnosis.pdf

42. Gonfiantini MV, Carloni E, Gesualdo F, Pandolfi E, Agricola E, Rizzuto $E$, et al. Epidemiology of pertussis in Italy: disease trends over the last century. Euro Surveill. 2014;19(40):20921. DOI: 10.2807/1560-7917.ES2014.19.40.20921 PMID: 25323077

43. Niessen WJ, Broer J, Schellekens JF. Meldingsplicht voor kinkhoest niet effectief om ongevaccineerde kinderen te beschermen. [The obligatory notification of pertussis is not effective for the protection of unvaccinated children].Ned Tijdschr Geneeskd. 2008;152(2):86-90. Dutch.PMID: 18265798

44. Meldingsnorm voor meldingsplichtige ziekten. [Notification norm for notifiable diseases]. (2017). Dutch. Available from: http://www.rivm.nl/Documenten_en_publicaties/ Algemeen Actueel/Uitgaven/Infectieziekten/ Meldingsnorm_voor_meldingsplichtige_ziekten

45. Verheij TJM, Hopstaken RM, Prins JM, Salomé PL, Bindels PJ, Ponsioen BP, et al. NHG-Standaard Acuut hoesten (eerste herziening). [NHG guideline on acute coughing]. Huisarts Wet. 2011;54(2):68-92. Dutch. Available from: https://www.nhg.org/ standaarden/volledig/nhg-standaard-acuut-hoesten

46. Teepe J, Broekhuizen BD, leven M, Loens K, Huygen K, Kretzschmar $M$, et al. Prevalence, diagnosis, and disease course of pertussis in adults with acute cough: a prospective, observational study in primary care. $\mathrm{Br}$ J Gen Pract. 2015;65(639):e662-7. DOI: 10.3399/bjgp15X686917 PMID: 26412843

47. Kauhl B, Heil J, Hoebe CJPA, Schweikart J, Krafft T, DukersMuijrers NHTM. Is the current pertussis incidence only the results of testing? A spatial and space-time analysis of pertussis surveillance data using cluster detection methods and geographically weighted regression modelling.PLoS One. 2017;12(3):e0172383. DOI: 10.1371/journal.pone.0172383 PMID: 28278180

\section{License and copyright}

This is an open-access article distributed under the terms of the Creative Commons Attribution (CC BY 4.0) Licence. You may share and adapt the material, but must give appropriate credit to the source, provide a link to the licence, and indicate if changes were made.

This article is copyright of the authors, 2017. 